\title{
Pattern of Neonatal Admissions and Outcome in an Intensive Care Unit (ICU) of a Tertiary Care Paediatric Hospital in Bangladesh - A One-Year Analysis
}

\author{
MS HOQUE ${ }^{\mathrm{a}}$, S ALAM ${ }^{\mathrm{b}}$, ASMNU AHMED ${ }^{\mathrm{c}}$
}

\begin{abstract}
Summary:
Objective: To describe the characteristics of neonates admitted to intensive care unit (ICU) and their outcome in a tertiary care paediatric hospital in Bangladesh.
\end{abstract}

Study Design: Retrospective, descriptive study.

Setting and Duration of Study: Paediatric intensive care unit in Dhaka Shishu Hospital from January to December 2011.

Methods: Data was retrieved from file records of all admitted neonates regarding age, gender, gestational age, birth and admission weight, reason for admission and outcome.

Results: During this study period, the total number of patients admitted was 191; most of them were neonates (146, 76.4\%). Among the 146 neonates, the highest number comprised of birth asphyxia (55, 37.7\%), followed by serious bacterial infections (sepsis, pneumonia, meningitis) (30, $20.5 \%)$ preterm low birth weight (LBW) babies (28, 19.2\%),

Introduction:

Neonatal period is the most vulnerable period of life. World Health Organization (WHO) estimates that 4 million neonatal deaths occur around the world every year. ${ }^{1}$ Approximately $98 \%$ of these deaths occur in developing countries, and are attributable to infections, asphyxia, and consequences of prematurity and low birth weight. ${ }^{2}$ Overall, neonatal mortality accounts for nearly two-thirds of infant mortality and one-third of underfive childhood mortality worldwide. ${ }^{3-5}$

Caring for the critically ill is a challenge in developing countries, where health needs often outstrip available

a. Dr. Md. Shafiul Hoque, MD, Assistant Professor of Paediatrics, Bangladesh Institute of Child Health, Dhaka Shishu Hospital

b. Dr. Syful Alam, MBBS, Mymensingh Medical College

c. Dr. A.S.M. Nawshad Uddin Ahmed, FCPS, Professor of Paediatrics, Bangladesh Institute of Child Health, Dhaka Shishu Hospital

Address of Correspondence: Dr. A.S.M. Nawshad Uddin Ahmed, FCPS, Professor of Paediatrics, Bangladesh Institute of Child Health, Dhaka Shishu Hospital, Sher-e-Bangla Nagar, Dhaka-1207, Cell: 01552-372200, E-mail: dr_nawshad@yahoo.com

Received: 7 January, 2013

Accepted: 16 March, 2013 surgical conditions (congenital diaphragmatic hernia, oesophageal atresia with trachea-oesophageal fistula, Hirschsprung disease and anorectal malformations) (18, $12.3 \%)$, respiratory distress syndrome (RDS) $(9,6.2 \%)$, and congenital heart disease (6, 4.1\%). Out of 146 patients, 42 expired (28.8\%). Most of the expiries were due to sepsis (35.7\%); followed by prematurity (21.4\%), perinatal asphyxia (19.0\%) and surgical conditions (14.3\%).

Conclusion: Birth asphyxia, septicaemia, and prematurity were the main reasons for neonatal admissions in ICU, while case fatality was highest for septicaemia. Regular antenatal visits, safe delivery practice and timely referral to tertiary care hospitals may result in decreased burden in ICU and also better outcome.

Keywords: Pattern of admission, Neonates, Paediatric intensive care, Outcome.

(J Banagladesh Coll Phys Surg 2013; 31: 134-139)

resources. ${ }^{6,7}$ Necessary equipment is scarce and often malfunctions, ${ }^{8,9}$ and trained manpower is limited. ${ }^{4}$ Management of critically ill patients requires significant human, infrastructural, and financial resources. These resources are typically limited in low-income countries.

A recent review highlighted the paucity of knowledge regarding critical care in the developing countries. ${ }^{10}$ Knowledge of the characteristics and outcomes of critically ill patients admitted to ICUs in low-income countries may help with the identification of priorities and the resources required for improvement of the care of critically ill patients in resource-limited regions of the world.

The aim of this study was to assess the major disease burden of neonates admitted to the intensive care unit at Dhaka Shishu Hospital and their hospital outcome. Having an idea of the type of disease burden commonly encountered in a particular unit, will help in future planning for the better management of such patients.

Materials and methods:

Study site: This retrospective descriptive study was conducted in the intensive care unit (ICU) of Dhaka 
Shishu Hospital (DSH), the largest paediatric hospital in Bangladesh for primary and tertiary care. The ICU has 10 beds and operates at full capacity at all times. The present capability is ventilating only four neonates at any one time. Surfactant is available but due to financial cost is not accessible to most of the babies; total parenteral nutrition is not readily available. Trained consultant paediatricians and residents are responsible for medical care of the neonates.

Study Population: A retrospective review of all patients admitted to the ICU at Dhaka Shishu Hospital over a period of one year (from January to December 2011) was undertaken. The hospital has no delivery facility, and all neonates were outborn.

Data collection: Information regarding admissions and outcomes were obtained from paediatric intensive care unit hospital record forms. The hospital record forms record the patient's name, hospital number, age and gender, patient management and where the patient was discharged to. Data obtained included the patient's age and sex, mode of delivery, history of birth asphyxia, birth and admission weight, the date of admission, diagnosis on admission, date of discharge, and length of stay, interventions if any, and outcome.

Statistical analysis: The data were subjected to statistical analysis according to standard procedure. SPSS version 12.0 for Windows (SPSS Inc, Chicago, IL, USA) software was used for data recording and analysis. Since it was a descriptive study, frequencies were determined.

Ethical issues: A permission to conduct this study was obtained from Dhaka Shishu Hospital authority.

\section{Results:}

A total of 191 patients were admitted into the ICU during the study period, among them 146 are neonates and are analyzed here. (Figure I) Among the neonates, there were 96 males and 50 females, male babies outnumbered their female counterpart with a ratio of 1.9:1. Ages on admission ranged from 1 to 28 days with a mean of $7.2 \pm 5.7$ days and median of 5 days. Seventy-eight babies (53.4\%) were born at home and 68 babies (46.6\%) were hospital born. The mode of delivery was mostly normal vaginal delivery (NVD) i.e., $77.8 \%$ and $22.6 \%$ lower uterine caesarean section (LUCS). Two-thirds of the admitted neonates (96/146, 65.7\%) came from outside Dhaka city. Admission weight ranged from $700 \mathrm{gm}$ to 4070gm (with a mean of 2328 $\pm 722 \mathrm{gm}$ and median of 2600gm).

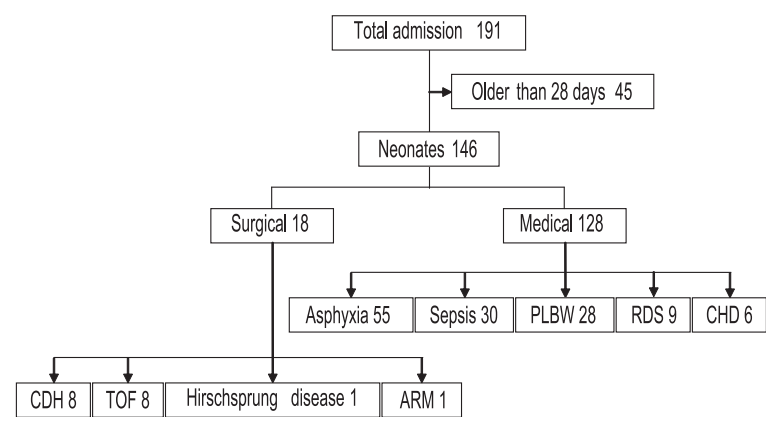

PTLBW=Preterm low birth weight, RDS=Respiratory distress syndrome, $\mathrm{CHD}=$ Congenital heart disease

$\mathrm{CDH}=$ Congenital diaphragmatic hernia, $\mathrm{TOF}=$ Trachea-oesophageal fistula, ARM= Anorectal malformation

Fig.-I: Flowchart showing the pattern of admission in the ICU $(n=191)$

The highest number of admissions comprised of birth asphyxia (55, 37.7\%); followed by serious bacterial infections (sepsis, pneumonia, meningitis) (30, 20.5\%), preterm, low birth weight (LBW) babies (28, 19.2\%), respiratory distress syndrome (RDS) $(9,6.2 \%)$, and congenital heart disease (6, 4.1\%). (Figures I and II) Eighteen surgical cases, $12.3 \%$ of all admitted neonates, were admitted for pre- and post-operative management. The surgical conditions include congenital diaphragmatic hernia $(n=8)$, oesophageal atresia with trachea-oesophageal fistula $(\mathrm{n}=8)$, Hirschsprung disease $(\mathrm{n}=1)$, and anorectal malformations $(\mathrm{n}=1)$.

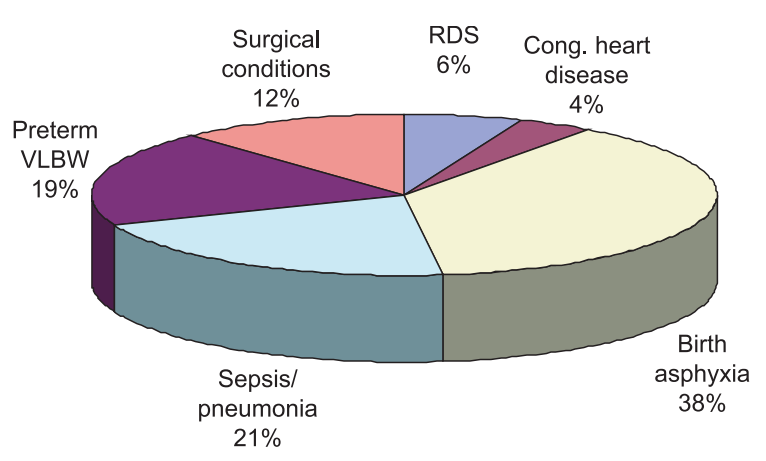

Fig.-2: Causes of neonatal admission in the ICU $(n=146)$ 
Table-I

Outcome of neonates admitted in the ICU by admission weight $(n=146)$

\begin{tabular}{lccccc} 
Admission weight $(\mathrm{gm})$ & Discharged & DORB & Died & Total & Mortality (\%) \\
\hline$\leq 1,0200$ & 2 & 0 & 4 & 6 & 66.7 \\
$1,001-1,500$ & 7 & 3 & 8 & 18 & 44.4 \\
$1,501-2,000$ & 13 & 2 & 8 & 23 & 34.8 \\
$2,001-2,500$ & 12 & 2 & 5 & 19 & 26.3 \\
$2,501-3,000$ & 43 & 6 & 15 & 64 & 23.4 \\
$>3000$ & 10 & 4 & 2 & 16 & 12.5 \\
\hline Total & 87 & 17 & 42 & 146 & 28.8 \\
\hline
\end{tabular}

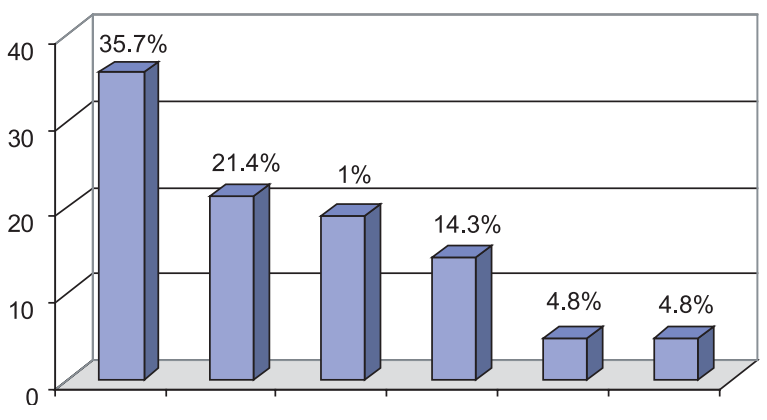

Fig.-3: Causes of mortality in neonates admitted in the ICU $(n=42)$

Length of stay in the ICU ranged from a few hours to 18 days, with a mean of $8.5 \pm 4.4$ days and median of 7 days. Analysis of outcome showed that out of 146 patients, 87 cases (59.6\%) were improved and transferred to the ward or discharged to home, 17 cases (11.6\%) left the hospital against medical advice (LAMA), and 42 expired (28.8\%). (Table I) Most of the expiries were due to sepsis, prematurity, perinatal asphyxia and surgical conditions. (Figure III) Eighteen cases developed manifestations of sepsis after admission in hospital and mortality was higher among these cases $(8 / 18,44.4 \%)$. Various comorbid conditions like congenital heart disease, respiratory distress syndrome, feeding intolerance contributed in mortality in some cases. Total thirty babies required ventilator support. Among them 13 babies could not be weaned off and expired, mortality rate of $43.3 \%$.

\section{Discussion:}

The benefits of neonatal intensive care are clear and there has been a dramatic fall in neonatal mortality in developed countries with the advent of mechanical ventilation and the concept of neonatal intensive care. ${ }^{11-}$ 13 But the appropriateness of ICUs in developing countries has been questioned, considering the fact that many of them face one economic crisis after another, ${ }^{6}$ but there are critically ill patients in most hospitals, whether in developed or developing countries. In Dhaka Shishu Hospital we do not have separate ICU for neonates, but in paediatric ICU majority of admissions (146/191; 76.4\%) during the study period were in neonatal age group. So the need of an NICU in a paediatric hospital is not over-ambitious.

This year long retrospective study was undertaken in order to document the most common type of diseases with which the neonates are admitted in the intensive care unit of Dhaka Shishu Hospital. Here birth asphyxia, sepsis and preterm, low birth weight babies account for the largest number of cases. The results of our study are comparable to a similar study done in Pakistan at the NICU of a tertiary care hospital in Karachi during 2006$7,{ }^{14}$ and another study done in Special Care Baby Unit (SCABU) of Bangladesh Institute of Research and Rehabilitation for Diabetes, Endocrine and Metabolic Disorders (BIRDEM) in 1995. ${ }^{15}$ 
It is estimated that around 23\% of all newborn deaths are caused by birth asphyxia, with a large proportion of stillbirths. ${ }^{16}$ Following improvements in primary and obstetric care in most industrialized countries, the incidence of birth asphyxia has reduced significantly and less than $0.1 \%$ newborn infants die from birth asphyxia. ${ }^{17}$ In developing countries, rates of birth asphyxia are several folds higher, ${ }^{18}$ and case fatality rates may be $40 \%$ or higher. ${ }^{19}$ Our study shows that still now an important cause of neonatal morbidity as well as mortality in our country is birth asphyxia. Home delivery by untrained birth attendants is the main reason for birth asphyxia, where more than $90 \%$ of all births occur in our country. ${ }^{20,21}$

Neonatal sepsis is a significant cause of neonatal morbidity and mortality in the newborn, particularly in preterm, low birth weight infants. ${ }^{22,23}$ Reports of the epidemiology of neonatal septicaemia from our country are few. ${ }^{24}$ The epidemiological data from other developing countries, however, shows important differences in the incidence, risk factors, pattern and antimicrobial sensitivities of pathogens and mortality from that of developed countries. ${ }^{25-27}$ The incidence of neonatal sepsis in the developed countries is 1-10/ 1000 live births, where as it is roughly three times more in developing countries like Bangladesh. ${ }^{24}$ In our study, septicaemia was the second most common cause of admission in ICU and the most common cause of death. Also many cases, who were not diagnosed as septicaemia on admission, later develop sepsis during hospital stay. Mortality was higher among these neonates. Newborns who are admitted to intensive care units (ICUs) are at a high risk for developing nosocomial infections, because of the severity of their illness and exposure to invasive medical devices and resistant microorganisms. ${ }^{28-30}$ The nosocomial infections among neonates result in substantial increases in morbidity, mortality, length of hospital stay, and costs. ${ }^{30,31}$

Low birth weight (LBW) is one of the leading problems in almost all the developing countries. ${ }^{32}$ Immaturity tends to increase the severity but reduces the distinctiveness of the clinical manifestation of most neonatal diseases. Immature organ function, complications of therapy and the specific disorders that caused the premature onset of labour contribute to neonatal morbidity and mortality associated with premature, LBW infants. The most important reason of mortality in VLBW infants is infections. Immature host defence mechanisms and invasive life support systems make the premature neonate particularly susceptible to overwhelming infection. Preterm LBW babies important contributors in the morbidity and mortality of neonates admitted in the ICU. Mortality was inversely related to admission weight. (Table I) It would give better information if we could see the mortality in respect to birth weight. But as more than half of the neonates were born at home, birth weight was not available for those cases.

The survival rate of $71.2 \%$ noted in this study for neonates in the ICU though less than that quoted for developed countries (91\%), ${ }^{13}$ compares favourably with figures quoted for other developing countries (46-54\%). ${ }^{33-35}$ Differences in mortality of neonates in ICU between developed and developing countries may be related to the ready availability of ventilator support, surfactant and parenteral nutrition in developed countries as compared to developing countries. Limited technical expertise and technological advances in developing countries may also be an added factor.

\section{Conclusion:}

Birth asphyxia, septicaemia, and prematurity comprised the major bulk of our ICU admissions, but many of these conditions could be averted by regular antenatal visits, safe delivery practice and timely referral of ill neonates to a healthcare facility. These measures would not only save lives of such babies, but also of those who don't get ICU facility at the time of need. However, to maximize on benefits versus cost in an atmosphere of budgetary constraint, evidence based management policies and protocols must be developed and implemented. 


\section{References:}

1. World Health Organization. Perinatal mortality. A listing of available information. Geneva, WHO 1996:32-6. (WHO/ FRH/MSM/96.7).

2. Black RE, Moris SS, Bryce J. Where and why are 10 million children dying every year? Lancet 2003; 361: 2226-34.

3. World Health Organization. Mother-baby package: implementing safe motherhood in countries. Maternal Health and Safe Motherhood Programme. Geneva, WHO 1994. (WHO/FHE/MSM/94.11).

4. Saving Newborn Lives. State of the World's Newborns. Save the Children Federation 2001; 1-49.

5. World Health Organization. Management of sick newborn. Report of a Technical Working Group, Ankara.

6. Watters D. Caring for the critically ill. Africa Health 1993; 16: $22-4$

7. Watters DAK. Organization and management. In: Watson DAK, Wilson IH, Leaver RJ, Bagshawe A, eds. Care of the Critically Ill Patient in the Tropics and Sub-tropics. London: Macmillan, 1992: 294-311.

8. Isamade ES, Yiltok SJ, Uba AF, Isamade EI, Daru PH. Intensive care unit admissions in the Jos University Teaching Hospital. Niger J Clin Pract 2007; 10: 156-61.

9. Oke DA. Medical admission into the intensive care unit (ICU) of the Lagos University Teaching Hospital. Niger Postgrad Med J 2001; 8: 179-82.

10. Adhikari NKJ, Rubenfeld GD. Worldwide demand for critical care. Curr Opin Crit Care 2011; 17: 620-5.

11. Williams RL, Chen PM. Identifying the source of the recent decline in perinatal mortality in California. N Engl J Med 1982; 306: 207-14.

12. Lee KS, Paneth N, Gartner LM, Pearlman MA, Grus L. Neonatal mortality: an analysis of the recent improvement in the United States. Am J Public Health 1980; 70: 15-21.

13. Richardson DK, Gray JE, Gortmaker SL, Goldmann DA, Parsley DM, McCormick MC. Declining severity adjusted mortality: evidence of improving neonatal intensive care. Pediatrics 1998; 102: 893-9.

14. Aijaz N, Huda N, Kausar S. Disease Burden of NICU, at a Tertiary Care Hospital, Karachi. Journal of the Dow University of Health Sciences Karachi 2012; 6: 32-5.

15. Nahar J, Zabeen B, Akhter S, Azad K, Nahar N. Neonatal Morbidity and Mortality Pattern in the Special Care Baby Unit of BIRDEM. Ibrahim Med Coll J 2007; 1: 1-4.

16. Lawn J, Shibuya K, Stein C. No cry at birth: global estimates of intrapartum stillbirths and intrapartum-related neonatal deaths. Bull World Health Organ 2005; 83: 409-17.
17. Badawi N, Kurinczuk JJ, Keogh JM, Alessandri LM, O’Sullivan F, Barton PR, et al. Intrapartum risk factors for newborn encephalopathy: the Western Australian case-control study. BMJ 1998; 317: 1554-8.

18. Kinoti SN. Asphyxia of the newborn in east, central and southern Africa. East Afr Med J 1993; 70: 422-33.

19. Bang AT, Bang RA. Diagnosis of causes of childhood deaths in developing countries by verbal autopsy: suggested criteria. The SEARCH Team. Bull World Health Organ 1992; 70: 499-507.

20. Ahmed S, Sobhan F, Islam A, Barkat-e-Khuda. Neonatal morbidity and care-seeking behaviour in rural Bangladesh. J Trop Pediatr 2001; 47: 98-105.

21. Islam MA, Chakraborty N, Khan JA. Program performance in areas served by government and non-government organizations. In: Bangladesh demographic and health survey, 1996-1997. Dhaka: National Institute of Population Research and Training, 1997: 1-37.

22. Stoll BJ, Hansen N. Infections in VLBW Infants: Studies. From the NICH Neonatal Research Network. Semin Perinatol 2003; 27: 293-301.

23. Stoll BJ, Hansen NI, Adams-Chapman I, Fanaroff AA, Hintz HR, Vohr B, Higgins RD. Neuro developmental and Growth Impairment among Extremely Low-Birth-Weight Infants with Neonatal Infections. JAMA 2004; 292: 2357-65.

24. Ahmed ASMNU, Chowdhury MAKA, Hoque MM, Darmstadt GL. Clinical and Bacteriological Profile of Neonatal Septicemia in a Tertiary level Pediatric Hospital in Bangladesh. Ind Pediatr 2002; 39: 1034-9.

25. Dramstadt GL, Black RE, Santosham M. Research priorities and postpartum care strategies for the prevention and treatment of neonatal infection in less developed countries. Pediatr Infect Dis J 2000; 19: 739-50.

26. Polin RA, St.Geme JWIII. Neonatal sepsis. Adv Paediatr Infect Dis 1992; 7: 25-61.

27. Waseem R, Izhar TS, Khan M, Qureshi AW. Neonatal Sepsis. Professional Med J 2005; 12: 451-6.

28. Brady MT. Health care-associated infections in the neonatal intensive care unit. Am J Infect Control 2005; 33: 268-75.

29. Auriti C, Maccallini A, Di Liso G, Di Ciommo V, Ronchetti MP, Orzalesi M. Risk factors for nosocomial infections in a neonatal intensive-care unit. J Hosp Infect 2002; 53: 25-30.

30. Zaidi AK, Huskins WC, Thaver D, Bhutta ZA, Abbas Z, Goldmann DA. Hospital-acquired neonatal infections in developing countries. Lancet 2005; 365: 1175-88.

31. Kawagoe JY, Segre CA, Pareira CR, Cardoso MF, Silva CV, Fukushima JT. Risk factors for nosocomial infections in 
critically ill newborns: a 5-year prospective cohort study. Am J Infect Control 2001; 29: 109-14.

32. Ahmed ASMNU, Rob MA, Rahman F, Rahman R, Huda N. Preterm Very Low-Birth Weight Babies: Outcome of Admitted Newborns at a Community-Level Medical College Hospital in Bangladesh. Journal of Bangladesh College of Physicians and Surgeons 2008; 26: 128-34.
33. Riyas PK, Vijayakumar KM, Kulkarni ML. Neonatal mechanical ventilation. Indian J Pediatr 2003; 70: 537-40.

34. Nangia S, Saili A, Dutta AK, Gaur V, Singh M, Seth A et al. Neonatal mechanical ventilation - experience at a level II care centre. Indian J Pediatr 1998; 65: 291-6.

35. Kambarami R, Chidede O, Chirisa M. Neonatal intensive care in a developing country: outcome and factors associated with mortality. Cent Afr J Med 2000; 46: 205-7. 